\title{
As armadilhas: bases discursivas da neuropsiquiatrização das LER
}

\author{
The trap: the discursive bases \\ of the neuropsychiatrization in RSI
}

Marilene Affonso Romualdo Verthein 1

Carlos Minayo Gomez 2

\footnotetext{
1 Departamento de Psicologia, Universidade Federal Fluminense. Rua Sinei Correa, lote 38, quadra 21, Niterói RJ. marilenevet@ig.com.br 2 Centro de Estudos de Saúde do Trabalhador, Escola Nacional de Saúde Pública, Fundação Oswaldo Cruz. Av. Leopoldo Bulhões 1480, Manguinhos, 21041-210, Rio de Janeiro RJ.
}

\begin{abstract}
The bases of neuropsychiatrization of the Repetitive Strain Injury. It's used as a reference to the polemic developed in Australia, in the 80's, dealing with: the iatrogenicity of the disease and the simulation by the patients; the sociopolitical implications of the diagnoses of chronical diseases and the psychiatric discourses used to define and mark the predisposition in the osteomuscular diseases that afflict the workers. It is considered that such orientations build a net of alliances that formed traps for nexus denial in the National Institute of Social Security/RJ in accordance with the practice instituted in other countries. Such strategies based on the cost reduction of the benefits tend to decharacterize the work element as a fundamental component in the generating process of such diseases.
\end{abstract}

Key words RSI, DORT, Subjectivity, Worker's health, Medical inquiry
Resumo Apresenta as bases da neuropsiquiatrização das Lesões por Esforços Repetitivos. Utiliza-se como referência à polêmica desenvolvida na Austrália, nos anos 80, versando sobre: a iatrogenia da doença e a simulação dos pacientes; as implicações sociopolíticas dos diagnósticos das doenças crônicas e os discursos psiquiátricos, utilizados para definir e marcar a predisposição nas doenças osteomusculares que atingem os trabalhadores. Considera-se que esses encaminhamentos montam uma rede de alianças que se constituiram em armadilhas para a negação do nexo no Instituto Nacional de Seguridade Social/RJ em consonância com a prática instaurada em outros países. Essas estratégias fundadas na redução de custos dos benefícios tendem a descaracterizar o elemento trabalho como componente fundamental no processo gerador dessas doenças.

Palavras-chave LER, DORT, Subjetividade, Saúde do trabalhador, Perícia médica 


\section{Introdução}

As lesões por esforços repetitivos (LER) tornam-se, a partir dos anos 90, cada vez mais, referendadas pela neuropsiquiatria. Esse novo enquadramento pôde ser observado pela nossa pesquisa, no INSS/RJ, a partir da apropriação e articulação do discurso da neurologia e da psiquiatria na análise das doenças osteomusculares relacionadas ao trabalho. Atentamos, inclusive, que essa referência às bases discursivas da neuropsiquiatria apresenta-se como uma armadilha, servindo à instituição previdenciária para negar o nexo dessa doença com o trabalho. Tal encaminhamento é reforçado pelas políticas de saúde restritiva e acumulativa estabelecidas em outros países. Portanto, as reduções dos benefícios previdenciários estão diretamente relacionadas às questões de reconhecimento suscitado pelo território das doenças do trabalho e, principalmente, pelos rumos atuais de sua descaracterização.

O livro Saúde e previdência. Estudos de política social traz um retrato paradoxal da articulação entre capitalização e doença, ao afirmar que: A previdência social vem privilegiando fundamentalmente o interesse do capital investido no setor e não o interesse dos beneficiários da previdência (Braga e Paula, 1981).

Essa lógica parece ecoar nas análises, após os anos 80 , como atestam os vários debates sobre a crise da previdência compilados no Boletim DIESAT (1981). O livro De que adoecem e morrem os trabalhadores? (Ribeiro e Lacaz, 1985), do mesmo órgão, na análise dos acidentes de trabalho, já evidenciava que as políticas da Previdência Social serviam-se de sistemáticas alterações na legislação para minimizarem os direitos dos trabalhadores, dificultando ou negando os benefícios acidentários.

São expressões de políticas econômicas neoliberais que afinam o aparato jurídico-institucional da Previdência Social com as diretrizes da concretização de um Estado mínimo e excludente. Tal proposta tem sido efetivada por ações que buscam concretizar a privatização dos benefícios acidentários: constantes cortes das verbas públicas para a saúde, freqüente negação dos benefícios, terceirização dos serviços públicos de assistência médica.

Nessa direção, a Previdência Social tem sido caracterizada, como informa o site brasileiro sobre o assunto, por crises financeiras não só no Brasil, mas na maioria das nações. Ora pela situação de esgotamento das fontes tradi- cionais de financiamento, ora pela generalizada elevação do déficit público, mas, principalmente, pelos investimentos em estratégias de políticas de saúde, de cunho economicista. Desta forma, salvo as particularidades desses investimentos nos diferentes países, as mudanças em saúde e trabalho mantêm as mesmas diretrizes básicas quanto ao aumento das taxas de contribuição e à redução dos benefícios.

Nos EUA, por exemplo, houve o aumento gradativo das contribuições de empregados e empregadores, até 1990, e a proposta de elevação gradual da idade mínima para a obtenção de aposentadoria, a partir de 2003. Na Inglaterra, o governo Thatcher preconizou uma profunda reforma do sistema previdenciário, mas acordos políticos permitiram apenas uma reforma gradual do sistema público e a criação de incentivos aos contribuintes para optarem por seguros privados. Essas reformas entraram em vigor em 1988 e tiveram como objetivo central reduzir os encargos e obrigações de longo prazo do sistema de seguridade social inglês. A Itália aumentou o limite de idade para aposentadoria, o tempo mínimo de contribuição e regulamentou aposentadorias privadas complementares. Mudanças semelhantes estão em curso ou em discussão em outros países do mundo, inclusive, pensando-se em um regime de capitalização com contas individuais que seria ampliado, também, para a América Latina.

Realmente, como pode ser percebido, nesse site da Previdência Social, o governo brasileiro não está inovando em nada ao propor a reforma do sistema previdenciário, mas apenas fazendo os ajustes necessários que várias nações do mundo já realizaram ou estão realizando.

Constatamos, porém, que esse caminho das reformas deixa a desejar quanto aos direitos trabalhistas sociais conquistados pelos trabalhadores ao longo da sua história e tem excluído, da globalizada reestruturação produtiva, não só os trabalhadores que adoecem, mas a própria doença do trabalho. Essa questão que privilegia o debate da crise da Previdência Social no âmbito da saúde pública prioriza, na atualidade, a retomada dessa discussão por vários segmentos sociais de forma a estabelecer estratégias que possam barrar essa natural privatização do seguro de acidente de trabalho.

São muitas e complexas as vias desse processo de naturalização; nossa pretensão, nessa estratégia de desnaturalização, focaliza-se nas discussões sobre as LER, que têm data similar ao início destas reavaliações previdenciárias da 
década de 1980. Essas doenças tornaram-se frutos desse grande impasse contemporâneo, ao ressaltarem, nas discussões entre saúde e trabalho, as questões do custo das doenças relacionadas ao trabalho e, mais especificamente, as trilhas de descaracterização do nexo quando apresenta o próprio trabalhador como "naturalmente" predisposto a esse processo de adoecimento.

Neste texto problematizamos as bases discursivas da neuropsiquiatrização das LER, no INSS/RJ, privilegiando não uma análise das razões socioeconômicas da negação do nexo, mas a produção de subjetividade constituída por tal procedimento.

Os dados sobre o INSS foram obtidos através de entrevistas com os médicos da Perícia Médica do INSS/RJ; com os trabalhadores lesionados que encaminhavam processos de requisição de nexo a essa Perícia e a partir da leitura e levantamento de dados dos respectivos processos, em pesquisa realizada no período de março de 1997 a dezembro de 1998.

Analisaremos, inicialmente, as redes discursivas que nos pareceram fortalecer o caminho trilhado pelo INSS/RJ no rastro das análises australianas sobre o tema.

\section{A reestruturação da análise australiana sobre as lesões por esforços repetitivos}

A denominação Repetitive Strain Injury - RSI, que designava as LER, na Austrália, indicava, inicialmente, desordem funcional e orgânica resultante de fadiga neuromuscular devido à execução de atividades em posição fixa e/ou em movimentos repetitivos dos membros superiores. Os sintomas mais freqüentes decorriam de dores, fraqueza e sensações de cãibra em um ou mais dos grupos de músculos das mãos, dedos, braços, ombros e pescoço. E eram reconhecidos como decorrentes das condições de trabalho, até que, segundo Ferguson (1987), as reivindicações profissionais incluídas em RSI passaram de "762 casos em 1978-1979 para 2.263 em 1981-1982".

Em decorrência, o governo australiano, preocupado com a incidência aumentada dos casos e dos custos inerentes a eles, buscou elaborar diretrizes para controle e prevenção, através da Comissão Nacional de Saúde e Segurança Profissional, criando uma força-tarefa em RSI, no serviço público. O Relatório Interino do Comitê de RSI foi publicado em julho de
1985 e, paralelamente, foram revistas as atitudes comunitárias para a doença, analisadas a experiência australiana e a internacional, elaboradas as estratégias preventivas e sistematizados os aspectos de diagnose, tratamento e reabilitação. Os pacientes foram submetidos aos mais variados tipos de testes clínicos ou imagéticos e a procedimentos terapêuticos, visando ao alívio das dores: fisioterapias, drogas antiinflamatórias, talas e tipóias, eletroterapias e cirurgias. Paralelamente, grandes investimentos foram efetuados para a investigação dos locais de trabalho e para sua melhoria ergonômica, trazendo aos pacientes não só benefícios físicos em postura e redução de carga osteomuscular dinâmica e estática, mas também benefícios psicológicos.

No mesmo ano da publicação do relatório, surgem as polêmicas entre investimentos e custos, iniciando-se um movimento de crítica, ilustrado no artigo de Awerbuch (1985) pela metáfora da Pata de Canguru (Kangaroo Paw) que, pejorativamente, questionava a alta incidência dos casos de RSI reconhecidos como doença do trabalho pelo Comitê de Saúde e Segurança Australiano, alegando que a patologia era desconhecida, as características clínicas difusas e a prognose incerta.

Segundo Ferguson (1987), a partir de 1986, percebe-se nas publicações do The Medical Journal of Australia que a análise dessa "epidemia australiana" deixa de lado as avaliações das tarefas repetitivas e das posturas inadequadas relacionadas ao trabalho e passa a enfatizar fatores mentais e sociais.

Assim, novos olhares deslocam as atribuições da causalidade e as atitudes em relação a RSI. Esta denominação começa a ser questionada como anacrônica e os sintomas de dores são atribuídos a fatores mentais e sociais, enfatizando, no distúrbio, o efeito de psicossomatização que afeta o sistema osteomuscular.

Este deslocamento na análise das RSI, na Austrália, é anunciado pela abordagem de alguns autores que, em grandes grupos, articulam uma rede discursiva de conceitos, mitos, valores e estratégias de ação: os discursos da iatrogenia e da simulação; os da doença crônica e os psiquiátricos, referentes à personalidade neurótica. 


\section{Rede discursiva de conceitos, mitos, valores e estratégias de ação}

\section{1) Os discursos da iatrogenia e da simulação}

As doenças iatrogênicas referem-se às doenças causadas por condições sociais e contrastam com as doenças originadas pela iatrogenia clínica, as quais decorrem de resultados de diretrizes para tratamento aplicadas por doutores em seus pacientes.

A discussão sobre a iatrogenia nas lesões por esforços repetitivos introduzida pelo texto "RSI: a model of social iatrogenesis", do médico reumatologista Cleland, em 1987, trata dessas duas formas de iatrogenia. Nesse texto, o autor considera que a Comissão Nacional de Saúde Ocupacional e Segurança Pública da Austrália, ao recomendar diretrizes e códigos, alertando sobre o uso correto dos teclados para prevenir as lesões por esforço repetitivo, acaba por reforçar, em contrapartida, tanto a expectativa da incapacidade quanto a ansiedade e a aflição criada pelo medo de adquirir a doença. Esse procedimento de prevenção, segundo o autor, tem provavelmente um papel causal no desenvolvimento dessa síndrome que pode, no entanto, ser vista também como um exemplo social de iatrogenia, ao servir para a obtenção de ganhos secundários.

Para Cleland, o diagnóstico de RSI, por enfatizar a lesão e associá-la ao processo de trabalho, permite aos trabalhadores perceber o "status de vítima de acidente" e, ao mesmo tempo, criar a expectativa de compensação monetária por seu sofrimento e incapacidade.

Essa crítica de Cleland focaliza o que denomina "ciclo vicioso" das lesões por esforços repetitivos. A atividade, compreendida como causa, leva o trabalhador a ter consciência da sensação de desconforto, gerando por antecipação, a dor. Este círculo, para o autor, é reforçado pelos terapeutas que, diagnosticando a lesão, aplicam terapia local e prescrevem, de forma radical, a imobilização dos membros superiores. Logo, conclui: O resultado é que evitar o exercício dos membros superiores pode ser um padrão orientado para desconforto e concernente apreensão do potencial de efeitos danosos que estão associados com ele. Sendo assim, um trivial desconforto pode tornar-se prolongado, doloroso e condição de incapacidade que exclui o trabalho efetivo e degrada a qualidade de vida. (Cleland, 1987).
Esse procedimento foi destacado, posteriormente, por Hall (1988) como "círculo dordescanso-dor", também creditado como reforço ao papel de doente, já que o trabalhador acaba por ser rotulado de incapaz ao permanecer um longo período de tempo afastado. Não considera os sintomas como uma forma de simulação com a finalidade de lucro, mas um caso de iatrogenia gerada pelo medo de uma nova lesão e pela expectativa de negação quanto ao seu retorno ao trabalho, por parte do empresariado.

Mas foi David Bell (1989) quem sistematizou os elementos que considerava iatrogênicos nesse processo de adoecimento:

- o atendimento de RSI como uma doença física, induzindo à comunidade a aceitá-la como uma lesão;

- os variados métodos de tratamento dispensados aos queixosos, levando-os a ter uma visão hipocondríaca do próprio corpo;

- a sintomatologia de RSI ser reconhecida como doença do trabalho pelo governo, influenciado e pressionado pelos sindicatos e pela comunidade em geral;

- o direito à compensação por danos osteomusculares sofridos no trabalho;

- as campanhas de alerta dos ergonomistas sobre o potencial de perigo do teclado.

Vamos destacar, desta lista, as implicações desses aspectos com o referencial psiquiátrico da articulação entre o adoecer e a personalidade do doente, pois consideramos que é, principalmente, por este caminho que estes autores procuram argumentar a idéia da predisposição ao adoecimento. Sob essa ótica, os trabalhadores que apresentam a sintomatologia de dores osteomusculares são em geral malingering, como os denomina Bell (1989), ao referir-se ao paciente que se finge de doente para não trabalhar. Para este autor, tal condição torna-se exacerbada, no caso dos RSI, pela existência de um sistema de compensação pelos danos sofridos no trabalho.

O sistema de compensação, como afirma Lucire (1986) corroborando com a idéia, serve de suporte para a epidemia da "neurose profissional". Esse sistema reforçaria o estado de incapacidade do trabalhador tanto na neurose simulada ou "artesanal", como na neurose dita ocupacional, ao permitir o afastamento do trabalhador do local de trabalho. Nessa lógica, pensa-se em reduzir o problema do afastamento dos pacientes com lesões osteomusculares, acabando com o direito à compensação por danos em RSI. 
Sendo assim, é entendido por estes autores que a prevalência da doença por simulação, ou até por prejuízo do trabalhador, cresce principalmente em circunstâncias ou sistemas em que "não se desencoraja esta forma de exploração" do trabalhador em relação ao sistema de compensação. Essa "forma de exploração" é referendada pela idéia de simulação do trabalhador. Desta maneira, a idéia da exploração está relacionada com a crença na simulação do trabalhador. Assim, estranhamente, esses autores, apontam que o trabalhador explora o governo, apropriando-se indevidamente dos benefícios da lei de indenização por danos no trabalho.

Dois fatos devem ser pontuados nessas análises: a total desconsideração quanto à pertinência das relações de trabalho nesse processo de adoecimento e a proposital argumentação, às avessas, dos fins a que se propõe a lei da indenização, com o intuito de descaracterizar as doenças relacionadas ao trabalho na inversão do dano (trabalho) pelo danoso (trabalhador).

Embora exista uma diferença básica nessas argumentações, posto que em Lucire (1986) a neurose é passível de determinações inconscientes e para Bell (1989), na maioria das vezes, o comportamento para obter ganhos secundários é consciente, os dois mostram subsídios de estudos psiquiátricos, sobre dados de personalidade dos pacientes, utilizando-os de forma maniqueísta para culpabilizar ou marginalizar as dores dos mesmos. Para Bell, o apropriado seria "encorajar o queixoso a continuar a trabalhar" pois as dores "são uma parte normal de viver" e este comportamento doente é apenas uma resistência de quem não quer trabalhar (Bell, 1986).

A idéia de malingering citada no texto "Repetition strain injury: an iatrogenic of simulated injury" pelo psiquiatra David Bell causou muita polêmica na época. Entre várias cartas de leitores do Medical Journal of Australia com congratulações (Dickinson, 1989) e apoio (Roberts, 1989), os créditos passavam pela alegação dos milhões de dólares gastos em "perda de tempo" com os trabalhadores que adoeciam no trabalho. Segundo Bell, era questionável que as condições de trabalho pudessem ser um elemento gerador nesse processo de adoecimento. Ao contrário, ele supunha que a ausência sistemática de concordância entre exames médicos e queixas indicava uma "fabricação" da dor. Concordando, Roberts, afirma que se os sintomas e sinais não podem ser correlacionados com o modelo médico aceitável, a diagnose de malin- gering pode ser feita, à medida que, a terminologia malingering, para ela, "pode ser vista como a consciência descarada da representação da proposta de ganho financeiro" (Roberts, 1989).

Outros médicos que atendem pacientes com LER criticam estas afirmações (Cullum, 1989; Hopkins, 1986). Consideram o artigo de Bell insensível por etiquetar quase todos os casos de danos de trabalho repetitivo na categoria de histeria e malingering. Embora concordem com a possibilidade de alguns pacientes apresentarem dores triviais, contrapõem essa idéia de generalização dos casos, afirmando que muitos pacientes com LER são acometidos de severo e permanente dano incapacitante. Eu tenho visto muitos pacientes que clinicamente tem óbvias patologias, as quais são demonstradas por investigações tais como o teste de isotopia, termografia e eletromiografia. Tais pacientes são avaliados por médicos que podem não encontrar nada de errado com eles e então tem a audácia de falar que a dor que eles estão experimentando é "toda mental" (...) preconceito comum de que os pacientes são culpados (Cullum, 1989).

Assim como Cullum que associa as dores das LER ao contexto do trabalho, Quintner (1989), também critica a posição de Bell, argumentando que o mesmo tem entendido de forma equivocada as bases do termo "neurose ocupacional" proposta por Gowers. Além disso, acusa Bell de ignorar, também, as condições de trabalho como elementos deflagradores de dor nos braços e pescoço entre os trabalhadores.

Podemos sintetizar que os autores Bell (1989) e Cleland (1987) não acreditam em RSI como doença, pois, para eles, a queixa do desconforto muscular pode acometer qualquer pessoa em algum momento de sua vida. Analisam os sintomas dos trabalhadores como modelos de simulação osteomuscular, ou seja, dores imaginárias de base comportamental, exibida com a obtenção de ganhos secundários. Outros autores, como veremos, acreditam nos RSI como doença, mas colocam a origem de sua ocorrência na predisposição do sujeito, o que caracterizaria os dados da doença crônica e degenerativa.

\section{2) Os discursos da doença crônica}

O ponto de vista da reumatologia em RSI enfatiza que as dores dos membros superiores são compreendidas como fibromialgias e síndromes de fadiga crônica que são clinicamente consideradas desordens enigmáticas. Para essa 
abordagem, todas as doenças do grupo dos RSI são psicossomáticas. $\mathrm{O}$ diagnóstico é baseado em cuidadoso exame clínico, na história ocupacional, no exame físico e na exclusão da doença reumática não ocupacional. Por outro lado, os diagnósticos de doenças reumáticas, tais como inflamações e artrites degenerativas, síndromes de dor cervicobraquial, podem ser diferenciados por critérios clínicos ou laboratoriais, mas podem coexistir com RSI.

Entre essas doenças crônicas podem estar as citadas por Hadler (1986), como as "doenças reumáticas industriais" e, em particular, a dor lombar. A relação entre a dor lombar e o acidente de trabalho foi apresentado durante a II Guerra Mundial através dos estudos sobre "ruptura de disco", isto é, lesões dolorosas lombares passíveis de cirurgia. Por serem as dores lombares associadas ao trabalho, o nexo passou a ser uma decisão política em relação a essa doença. Sendo assim, a descrição das tarefas passou a estabelecer a causa do dano e a responsabilidade do empregador.

A dor lombar é uma dor comum nas rotinas de trabalho, mas o excesso de força muscular estática ou dinâmica pode levá-la ao estado de uma síndrome de doença crônica.

Eu estou convencido de que as conclusões ocupacionais de causalidade de tarefa e culpa do empregador predispõem uma pessoa trabalhadora com dor lombar a se tornar uma pessoa reclamante. A dor lombar é dolorosa e quase todo o exercício excessivo exacerba o desconforto, de forma que algum grau de incapacidade de trabalho torna-se inevitável (Hadler, 1986).

Há, portanto, como assinala o autor, uma compreensão sociopolítica dessas hipóteses quando a dor lombar, categorizada como um acidente de trabalho, redefine os pré-requisitos para a compreensão da doença, já que é possibilitado o benefício acidentário pelo seu diagnóstico como manifestação de incapacidade no trabalho.

Uma análise sociopolítica das doenças implica colocar as relações de trabalho que adoecem em discussão, da mesma forma que os encaminhamentos diagnósticos, tratamento de cura e suas possibilidades de acesso na rede pública e particular. Todavia podemos considerar que, tanto na Austrália quanto no INSS/RJ, os encaminhamentos têm apresentado uma compreensão fechada na idéia da predisposição, principalmente, psíquica. A afirmação de Bell (1989) transcrita a seguir mostra essa ênfase: $A$ consecutiva série de pacientes com RSI que são examinados por um psiquiatra ou tem doença psiquiátrica ou histeria. Muitos dos pacientes que têm sido encaminhados ao meu consultório têm tido distúrbio de personalidade.

\section{3) Os discursos psiquiátricos da personalidade neurótica}

Essas discussões dos aspectos de uma personalidade neurótica em RSI foram apontadas no texto "Neurosis in the workplace", de Yolland Lucire, em 1986. A RSI seria um tipo específico de "epidemia de doença psicogênica em um passivo e dependente grupo" (Lucire, 1986), expressa como uma forma de histeria: Tal epidemia pode ser entendida à luz de teorias aceitas de contágio histérico. Os sintomas tornam-se epidêmicos quando a situação não é controlada corretamente e a convicção histérica permitida prevalece. A aceitação do indivíduo de tal convicção sustenta que ofator causal no desenvolvimento dos sintomas é governado pelo desejo das conseqüências do acreditar. A intensidade deste desejo é uma função da necessidade inconsciente para regressar a enfermidade e esta necessidade é governada por fatores de vulnerabilidade pessoais e circunstanciais.

Esta idéia de RSI como psicogênica seria explicada por quadros de personalidade ansiosa que, em condições sociais e culturais estressantes, levam os pacientes a demonstrar um comportamento simbólico da dor, por serem incapazes de reelaborar a angústia básica desse comportamento. Neste entendimento, afirmase como falsa a crença de que os movimentos de esforços repetitivos possam ser a causa das lesões. No caso de RSI, os sintomas são explicados pela manifestação somática de uma perturbação emocional, que por sua vez, é causada por idéias, crenças e emoções.

Baseando-se nas antigas análises do neurologista William Gowers, datadas de 1888, Lucire tenta estabelecer um paralelo entre a história da cãibra de escritor e a RSI, buscando incluir a RSI na mesma classificação diagnóstica de neurose ocupacional, apresentada na época, para descrever a cãibra de escritor. O paralelo é reforçado pela noção de predisposição. Nesta, o trabalhador seria portador de um mal que poderia ou não emergir sob determinadas condições de ansiedade. Essa predisposição é traduzida pelo tipo de temperamento que, no caso das cãibras dos escritores, foi descrito como "distintamente nervoso, irritável, sensível e resistente ao excesso de trabalho e a grave ansie- 
dade". Esta ansiedade, por sua vez, seria mantida como estopim a ser detonado "frente a problemas familiares, preocupação nos negócios ou pesadas responsabilidades".

$\mathrm{Na}$ cãibra de escritor, a dor era referida a várias partes do pulso e do braço, apresentando, além de cãibras, espasmos, tremores, descoordenação, parestesia, fadiga e fraqueza. Essas dores, no entanto, eram desvinculadas de qualquer relação com o trabalho.

Lucire faz, também, um paralelo entre a RSI e a epidemia conhecida, na América e na Inglaterra, como cãibra de telegrafista. Em 1908, o termo cãibra de telegrafista servia para definir o desenvolvimento de doença osteomuscular originada pelos movimentos rápidos da telegrafia.

Essa cãibra de telegrafista, considerada como uma doença de trabalho, era coberta pelo Ato de Compensação Britânica. O aumento dos casos que apareciam gerou a criação de um comitê para avaliação do trabalho telegráfico. No curso das investigações, foi apresentada a instabilidade nervosa como relacionada à repetição dos movimentos do telegrafista. Todavia, o relatório final dessa avaliação concluirá que a quantidade de fadiga requerida para a cãibra é decorrente, tão somente, de "fator pessoal" e que a epidemia poderia ser resolvida por uma "seleção cuidadosa e prudente de pessoal".

Com base nessas conclusões, Lucire fundamenta as origens psicogênicas da RSI e lista elementos que poderiam ser vinculados, entre si, para manter os mecanismos neuróticos: conflitos familiares, desejos imaturos, raiva das condições de trabalho, trabalhar em longas jornadas, frustração e decepção quanto à melhoria trazida pela tecnologia.

Essa abordagem também criou muita polêmica e entre os que a defendem, como Awerbuch e Morgan, e a rejeitam como Hay, é expressiva a fala desse último: O clube australiano das mãos, dr. Awerbuch, dr. Dinning, dr. Morgan e dr. Dodd parecem ser vitimas de seus próprios egos. O que eles não entendem eles indicam como recusa neurótica. Sou freqüentemente duro sobre as declarações deploráveis de meus colegas, para poder convencer meus pacientes que eles não são neuróticos (Hay, 1986).

Apresentamos estes enfoques, tão polêmicos em relação ao desenvolvimento das doenças osteomusculares relacionadas ao trabalho, não para afirmá-los, mas para problematizarmos sua pretensa atribuição de desenvolvimento natural dos diagnósticos das lesões por es- forços repetitivos que acometem os trabalhadores. Essas redes discursivas servem de armadilha ao tecerem os diagnósticos de RSI em um emaranhado neuropsiquiátrico, com o propósito de descaracterização total de qualquer nexo desta doença com o trabalho, assunto que aprofundaremos mais adiante.

Podemos questionar, tomando por base toda a polêmica das LER, como uma doença do trabalho passa a ser reduzida a um enfoque totalmente psicológico e, ainda, as implicações desse viés psiquiátrico para a total negação do nexo.

\section{Implicações do viés psiquiátrico na saúde do trabalhador}

Os ingredientes políticos, culturais, econômicos, psicológicos, sociais, jurídicos e religiosos marcam dispositivos de poder e saber na construção de um sentido para o trabalho, de uma eficácia para o corpo, de um tipo de personalidade que será enquadrada como útil ou inútil na sociedade, em períodos históricos determinados.

A vinculação psiquiatria-Estado, apresentada como dado histórico da apropriação da psiquiatria como forma de controle e disciplinarização, serviu, no final do século XIX, à construção de uma determinada subjetividade do trabalhador. No Brasil, essa ligação pôde ser verificada no projeto de profilaxia social desenvolvido a partir da elaboração do Regulamento Sanitário Federal de 1923 e da Liga Brasileira de Higiene Mental. Esses regulamentos incluíam, no âmbito da saúde pública, as questões de higiene industrial e profissional, no sentido de ordem e progresso, e a precaução contra a presença do "perigo genético das raças impuras”. Na época, a higienização, fundamentada na teoria da degenerescência psíquica, marcava no corpo o destino genético e moral, tomando como alvo de assepsia o que era identificado como conduta "anti-social", a saber, os corpos que subvertiam a verdade e a moral. Os trabalhadores, os mendigos, as prostitutas e os alcoólatras eram visualizados e conceituados como "raças impuras", pois: Paulatina, mas perceptivelmente, no discurso como nas práticas da medicina mental, o objeto central de atenção e preocupação deixa de ser o louco ou o limítrofe. Ou melhor, limítrofes, degenerados... ganham, desde a segunda metade desta década, um único rosto: o do operariado urbano (Cunha, 1986). 
O trabalhador passa, assim, a ser objeto do olhar médico-psiquiátrico, pois como propõe o dr. Pacheco Silva, diretor do Juquery, em 1937, era importante para a criação do Ministério Único de Higiene, Assistência, Previdência e Trabalho "desenvolver o vigor e a boa vontade dos trabalhadores” (Cunha, 1986).

Essa é uma tecedura sofisticada e complexa da bifurcação entre os dois movimentos: da medicina social, como produtora e mantenedora de um corpo economicamente sadio e normal, e de uma psiquiatria médica que normatiza e regula essa normalidade pelo viés da capacidade produtiva, colocando o psiquismo como objeto de estudo.

Uma apreciação histórica sobre o encontro da medicina e o psíquico pode ser obtida no livro de Birman (1980) sobre Enfermidade e loucura nos fornecendo bases teóricas para um maior entendimento dessa intervenção - medicina e psíquica - nas LER.

A partir da II Guerra Mundial, uma medicina denominada antropológica pretende superar uma medicina estritamente orgânica, argumentando que a doença teria uma causalidade não só biológica, mas também psicológica, sociológica e antropológica. Nesta perspectiva, a dimensão do enfermo e da comunidade em que vive passa a ter lugar no discurso médico até então dedicado à enfermidade. Com a criação da Organização Mundial de Saúde, a saúde passa a ser definida como "um estado completo de bem-estar físico, mental e social". Diretrizes similares foram criadas nas recomendações 67 e 69, na Filadélfia, em 1944, pela Conferência da Organização Geral do Trabalho. Por outro lado, também tentando ultrapassar uma medicina puramente biológica, a medicina psicossomática emerge nos anos trinta, nos EUA, nos trabalhos do Instituto Psicanalítico de Chicago, postulando uma causalidade psíquica e não social da enfermidade. Estas duas vertentes sociológica e psicológica são associadas nos anos cinqüenta: Vitalismo e personalidade seriam as duas dimensões de uma mesma problemática, elaboradas em planos diversos do conhecimento, mas destacadas de um mesmo solo: as regulações adaptativas do indivíduo no seu espaço social (Birman, 1980).

Nesse caso, a adaptação do indivíduo ao seu meio de trabalho firma-se como exigência básica de saúde na polaridade médica do normal e do patológico. $\mathrm{Na}$ abordagem da patologia social, o normal e o anormal não se restringem ao diagnóstico, mas marcam o desvio social ou o virtual da anormalidade, isto porque: Se no momento originário a psicanálise e a sociologia se opuseram à medicina e à psiquiatria, serão por elas parcialmente colonizadas na modernidade, através do discurso das inter-relações (Birman, 1980).

Uma "psiquiatrização da medicina” (Birman, 1980) permite que práticas e saberes psiquiátricos forneçam os critérios de uma nova percepção da enfermidade, da terapêutica e da cura, principalmente devido a causas psicológicas no campo das doenças somáticas. As instituições sociais, a família, a escola, as indústrias, os hospitais, o trabalho são lugares estratégicos na realização do controle social das individualidades e das comunidades pela psiquiatrização das inter-relações entre os grupos sociais.

Esse deslocamento da doença como um mal que se apropriava do corpo, para uma enfermidade compreendida a partir das relações intersubjetivas e sociais, foram os elementos básicos para a condição de possibilidade da psicossomática, quando o discurso psicológico passou a matizar as dores do corpo pelas emoções.

Nesta perspectiva, os diagnósticos dos trabalhadores são mediados pelos objetivos organizacionais de eficácia produtiva e as emoções patologizadas no registro de uma impossibilidade de ajuste entre o indivíduo e o seu trabalho. No período do final do século XIX até a II Guerra Mundial, as racionalizações do trabalho sustentadas por Taylor, Ford e Fayol dão a tônica da relação entre eficiência e produtividade. Após a II Guerra Mundial a ineficácia produtiva foi localizada no comportamento do trabalhador, fazendo do discurso das relações humanas uma diretriz para solucionar conflitos entre expectativas institucionais e pessoais. Através do dispositivo das inter-relações, os problemas das relações de trabalho são encarados como pessoais e transformados em problemas psicológicos.

Observamos, na nossa pesquisa no INSS/RJ, que essas leituras das emoções pelo patológico, para assegurar a pureza racional da produtividade foram apropriadas pelos peritos, servindo de ferramenta para a prática da negação do nexo das LER, aqui no Brasil. 


\section{A prática da negação do nexo das LER, no INSS/RJ}

Na prática do INSS/RJ, vão aparecer alguns pressupostos que, do nosso ponto de vista, são subsidiados pelas redes discursivas de conceitos, valores, mitos e estratégias apresentados pela discussão da Austrália em relação aos encaminhamentos da Repetitive Strain Injury e que estão bastante engendrados nessa articulação de problemas de trabalho que se transformam em problemas pessoais e psicológicos. Não no sentido de uma integração subjetiva no enlace entre sujeito e meio, mas em uma construção de um sujeito que adoece, independente do meio e das condições em que vive.

Destacamos entre esses pressupostos básicos:

1) Os custos com as indenizações pagas aos trabalhadores em auxílio-acidente levam o INSS/RJ a uma busca desenfreada de descaracterização das LER como doença do trabalho. "Acabam os benefícios e acabam as LER" (médico perito).

2) Os diagnósticos são baseados em classificações de doenças crônico-degenerativas e psiquiátricas.

3) Indicam a especificidade de um tipo de "sujeito predisposto ao adoecimento".

Estudamos esse caminho do INSS/RJ, analisando os dados de 168 prontuários de telefonistas (74) e bancários (94) que requisitavam o B-91, código do INSS que defere o nexo da doença adquirida pelo trabalhador com o trabalho que realiza. Registramos, em quadro demonstrativo, as diferenças entre os diagnósticos informados na Comunicação de Acidente de Trabalho (CAT), os laudos dos médicos conveniados pelas empresas e os laudos dos peritos. Em todos os casos analisados, o B-91 foi negado e a maioria com a justificativa de "doenças crônico-degenerativas".

Transcrevemos, abaixo, um recorte do quadro "Laudos dos processos encaminhados para análise do nexo das LER, no INSS/RJ", querendo exemplificar algumas diferenças entre os registros.

Pode ser observado, no quadro 1, que as abordagens do INSS/RJ descartam os fatores lesivos do trabalho do processo de adoecimento das LER e enfatizam os laudos com aspectos ditos psicogênicos, tais como, doenças crônicas e degenererativas.

No levantamento mencionado, o INSS/RJ apresentou 108 (64,29\%) laudos em um total de 168 processos, ficando, portanto, $60(35,71 \%)$ processos arquivados sem resposta. Uma proporção de quase $1 / 3$ de casos arquivados, por certo mereceria um maior questionamento institucional. Não tivemos acesso, em nossa pesquisa, a informações relativas a esses casos, nem sobre os motivos da grande demora nos casos pendentes.

Entretanto, entendemos que esse arquivamento de casos fortalece a negativa radical do nexo da doença com o trabalho, como uma estratégia para a diminuição dos custos com benefício acidentário, ao criar um processo burocrático de adiamento das requisições do B91, tornando o envolvimento dos trabalhadores com o INSS/RJ desgastante e frustrado. Alguns trabalhadores e, até mesmo, alguns representantes das empresas no INSS chegam, às vezes,

\section{Quadro 1}

Laudos dos processos encaminhados para análise do nexo das LER, no INSS/RJ

\begin{tabular}{|c|c|c|}
\hline CAT & Convênio médico & INSS/RJ \\
\hline Síndrome do túnel do carpo & Síndrome do túnel do carpo & $\begin{array}{l}\text { Tenossinovite endógena degenerativa, sem relação } \\
\text { com a atividade. Nega B-91. }\end{array}$ \\
\hline Síndrome do túnel do carpo & Síndrome do túnel do carpo & $\begin{array}{l}\text { Síndrome do túnel do carpo, doença endógena } \\
\text { degenerativa. Nega B-91. }\end{array}$ \\
\hline Tenossinovite nos punhos e mãos & Síndrome do túnel do carpo & Cervicobraquialgia. Doença degenerativa. Nega B-91. \\
\hline Síndrome do túnel do carpo & Síndrome compressiva distal do punho & $\begin{array}{l}\text { Alterações posturais degenerativas da coluna cervical. } \\
\text { Nega B-91. }\end{array}$ \\
\hline Tenossinovite de Quervain & De Quervain à direita & $\begin{array}{l}\text { Tenossinovite e tendinite, osteofitose, uncoartrose. } \\
\text { Doença degenerativa. Nega B-91. }\end{array}$ \\
\hline LER & Tenossinovite do membro superior & $\begin{array}{l}\text { Uncoartrose, osteoartrose endógena. } \\
\text { Doença degenerativa. Nega B-91. }\end{array}$ \\
\hline
\end{tabular}

Fonte: INSS/RJ 
a pensar que não adianta recorrer ao nexo, quando os diagnósticos do trabalhador são as LER.

Entre os 108 casos, 50,93\% dos laudos foram estabelecidos em diagnósticos de doenças crônicas e degenerativas, tais como, artroses, osteofitoses, cervicobraquialgias, uncoartroses, apresentados, freqüentemente, juntos. Entre esses, 25\% foram, também, associados aos quadros osteomusculares vinculados às LER, principalmente, tenossinovite e síndrome do túnel do carpo. Essa direção diagnóstica facilitou a apropriação da idéia de predisposição do sujeito ao adoecimento tornando singular a distribuição dos casos, como pode ser visto no quadro 1 "Laudos - INSS/RJ".

Para uma melhor visualização da nossa hipótese sobre a similaridade entre a postura atual do INSS/RJ sobre LER e os textos da discussão da Austrália sobre RSI, complementamos o levantamento dos dados contidos nos prontuários com os dados das entrevistas que realizamos com os médicos peritos e com os trabalhadores com LER, também realizadas no mesmo período do levantamento de dados, o que nos forneceu uma outra diagramação dos fatos, projetada na figura 1 "INSS/RJ - trilhas de análise".

$\mathrm{Na}$ figura 1, verificamos que a classificação doença crônica e/ou degenerativa, acaba envolvendo - na condição de crônica 15,74\%, de degenerativa $8,33 \%$ e de ambas $75,93 \%$ - todos os casos. Assim, todos os processos são indeferidos pela análise da categoria da predisposição. A predisposição será orgânica, quando for considerado que o trabalhador adoece por problemas de estrutura orgânica, como, por exemplo, idade, traumas físicos anteriores, hereditariedade; e psíquica, se considerada uma predisposição emocional.

Os artigos da Austrália, sobre RSI, que utilizaremos para comparação, mostram os seguintes encaminhamentos: $44 \%$ classificando a doença como doença crônica; $29 \%$, como somatização de dores; $21 \%$, como resultado de iatrogenia social e simulação e, apenas, $6 \%$ relacionando o processo de adoecimento com o trabalho e referenciado na análise ergonômica. A figura 2 "Austrália - trilhas de análise" mostra essa distribuição.

Se compararmos as figuras 1 e 2 , vemos que os diagnósticos enquadrados em doenças crônicas e degenerativas são expressivos tanto no INSS/RJ (50,93\%), quanto na Austrália (44\%), para a classificação de doença crônica. A especificidade do laudo da somatização que pressu- põe um certo tipo de personalidade, com 29\%, na Austrália, pode ser, também, associada à posição do INSS/RJ que coloca a degenerescência e o crônico nos termos da predisposição do sujeito ao adoecimento, no entendimento de um sujeito com características subjetivas que o levam a adoecer orgânica ou psiquicamente. Esta projeção dos dados nos indicaria 75,93\% no INSS/RJ e 73\% na Austrália. O item da iatrogenia e da simulação, que apreciamos bem delimitados na Austrália, com 32\%, só foram observados no INSS/RJ através das posições dos peritos que, nas entrevistas sobre as LER, argumentavam que alguns trabalhadores adoeciam visando ganhos secundários. Esta idéia corresponderia à citação de Bell quando classifica os pacientes de RSI, como malingering.

No INSS/RJ, foram citados diagnósticos osteomusculares mais conhecidos nos quadros tradicionais da medicina, tais como, as tendinites, tenossinovites, síndrome do túnel do carpo, com 33,33\% de freqüência, mas, no laudo geral, cada uma destas classificações era associada aos quadros de doença crônica $(6,48 \%)$, degenerativa $(1,85 \%)$ ou a ambas $(25 \%)$, sempre sem relação com o trabalho e, freqüentemente, analisados como uma predisposição psíquica associada a somatização de dores.

As falas dos médicos peritos sobre a própria compreensão da doença mostram essas especificidades nos encaminhamentos das LER:

Muita coisa subjetiva; dor e impotência funcional (sem espessamento de tendão, sem edema, sem atrofia, sem dificuldade de potência muscular, sem seqüela) - (médico perito do INSS/RJ).

Tentam [na Austrália] mostrar justamente isso, que não tem muita relação com o trabalho, tem relação com a própria pessoa é pessoal (médico perito do INSS/RJ).

Eu acho que isso está sendo manipulado para botar rótulo no desemprego (médico perito do INSS/RJ).

(...) ou por ouvir dizer que o vizinho, o amigo, o parente tem uma sintomatologia, a pessoa começa a sentir essa mesma coisa e procura uma maneira de caracterizar (médico perito do INSS/RJ).

As várias expressões de dor e sofrimento são possibilitadas por uma determinada cultura que, interpretando e dimensionando padrões de conduta esperados e rejeitados, permite o acesso e a disponibilidade de relações no meio social, ou seja, na família, no trabalho, nas instituições. Além disso, as regras de normalização e regulamentação de uma determinada so- 
Figura 1

INSS/RJ - trilhas de análise

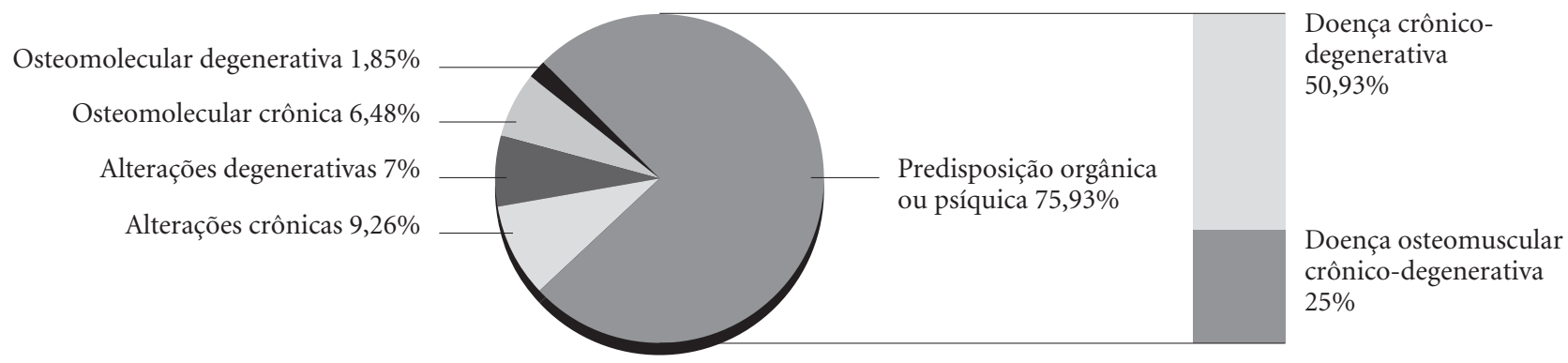

Figura 2

Austrália - trilhas de análise

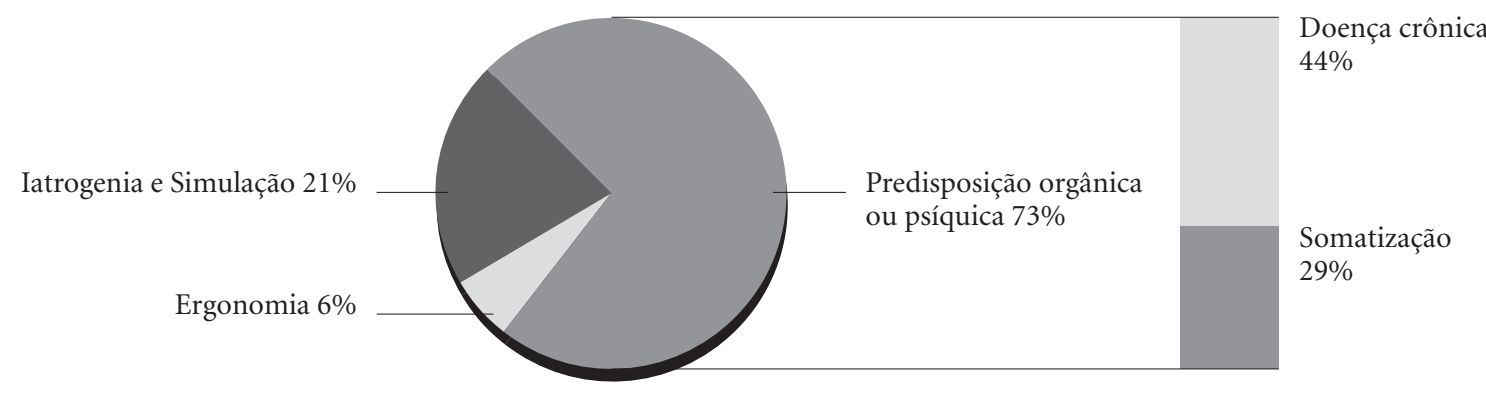

ciedade acabam por definir de maneira bem estabelecida os comportamentos ditos desviantes, anormais ou doentios, sempre engendrando modos de subjetividade para a sua expressão. Essa seria a possibilidade do entendimento de uma doença poder ser enquadrada em um determinado perfil de subjetividade e estaria associada a sintomas físicos ou não.

Este tipo de subjetividade enquadrada supõe um dispositivo de poder e, assim, podemos pensar em desejos capturados pela codificação social mas, também, na possibilidade das subjetividades que escapam aos papéis por uma geografia de conexões e disjunções inconscientes.

Vamos considerar que as interpretações dadas ao processo de adoecimento das LER codificam o trabalhador que adoece em um código preestabelecido como alguém simulador, de temperamento borderline, de histérico vindo a ameaçar a idéia de um trabalho asséptico sem desvios, paradas, incertezas.

As falas das trabalhadoras com LER exemplificam essas relações sociais, institucionais e pessoais com o processo de adoecimento no trabalho:

Eu fui do banco 15 anos. Fui demitida há um ano. Comecei a sentir dor em dezembro de 96 e engessei o braço diversas vezes. Em janeiro fiz exame periódico, estava já usando esta luvinha, em fevereiro trabalhei só 10 dias, fiquei os outros dias com o braço engessado e em maio/97 fui demitida (trabalhadora).

Muitos tem preconceito e não acreditam no que estamos sentindo (trabalhadora).

São as dores não visíveis e muitas vezes negadas que, interferindo na eficácia do trabalhador, impulsionam a sua demissão. Nesta circunstância, o nexo é muitas vezes negado e o 
trabalhador perde o direito à assistência, ao tratamento ou à reabilitação que são associados ao benefício a que faz jus quando adoece. Permanece o atendimento dado pelo SUS, mas, neste caso, devido ao sucateamento da rede de saúde pública, o tratamento e a assistência tornam-se assistemáticos e o quadro do trabalhador cada vez mais complexo. Chega-se, desta forma, a um descompromisso total com o trabalhador que adoece; é a radical separação entre processo de adoecimento e condições de trabalho que fazem adoecer.

Assim, podemos imaginar que a possibilidade de adoecer no trabalho é negada no próprio cotidiano das relações. A rejeição dos colegas de trabalho e das chefias é explícita quando o trabalhador que adoece é visto como alguém que faz corpo mole para não trabalhar. Da mesma forma, quando o trabalhador é tratado pelo médico como alguém que está somatizando conflitos psíquicos ou simulando a condição de doente para obter ganhos secundários. A partir dessas premissas, as explicações são as mais variadas: os trabalhadores ficam doentes porque há recessão na oferta de emprego, ou adoecem porque buscam estabilidade financeira e/ou segurança pessoal, via seguro acidentário ou, ainda, simplesmente, adoecem porque não querem trabalhar.

Algumas falas do INSS/RJ podem também ser encaixadas nestes enunciados em relação à doença:

Porque estão demitindo, todo dia tem processo (médico perito do INSS/RJ).

Muita gente fica desempregada e recorre ao INSS (médico perito do INSS/RJ).

Existe a doença e existe muita apelação pelo desemprego. Pessoas que não são digitadoras que não trabalham ininterruptamente estão requerendo (médico perito do INSS/RJ).

Acredito que o país hoje esteja passando por sua fase mais crítica, situação com relação à situação de desemprego, situações de mudança, privatização na área estatal, isto tem gerado uma síndrome que eu chamo de uma busca de regulamentação, uma busca de direitos dos trabalhadores (médico perito do INSS/RJ).

Embora trazendo uma falsa questão, a partir da afirmação de que o trabalhador passa a forjar uma doença para proteger-se de problemas socioeconômicos, podemos considerar que a premissa é verdadeira, ou seja, não podemos negar que o desemprego está cada vez maior, as oportunidades de trabalho mais restritas e as limitações osteomusculares sofridas pelos tra- balhadores com Lesões de Esforço Repetitivo são, sem dúvida, elementos redutores das chances de concorrência em um mercado de trabalho enxuto.

Entretanto, a questão não é tão simples. O trabalhador queixa-se de sintomas de uma doença do trabalho que o afeta e, ao começar a demonstrar os sinais da doença - baixo tonos, fraqueza na musculatura, parestesia, paralisia, e mesmo, medo, ansiedade, tristeza, insegurança, em função da própria condição que o aflige - cai no campo da psiquiatria. A tal ponto de os pacientes acometidos com as LER não terem seus diagnósticos associados ao seu histórico precedente de trabalho, mas a um tipo de personalidade que, em condições especiais de tensão e conflito, tornar-se-ia mórbida.

\section{A afirmação do nexo como uma forma de resistência à descaracterização das LER}

Esse encaminhamento envolve alguns pressupostos sobre um tipo determinado de personalidade que engendraria um "sujeito-doente", a partir da idéia de um perfil mórbido:

1) Os distúrbios osteomusculares, comuns nos trabalhadores que executam atividades de esforço muscular e repetitividade, são analisados sem o reconhecimento do trabalho na deflagração da patologia, por serem considerados em grandes grupos de doenças crônicas ou degenerativas que podem acometer as pessoas em geral.

2) A existência de uma personalidade que predispõe o trabalhador, em situações de conflito e tensão, a processos de adoecimento. As dificuldades no trabalho, assim como as pressões de instabilidade social, estariam entre os elementos ansiogênicos.

3) As LER não seriam propriamente "doenças”, mas um conjunto de sintomas de doenças dos nervos ou de estresses que acometeriam determinados "sujeitos predispostos" a transtornos mentais ou somatizações.

Assim, a idéia de um "sujeito-doente" pressupõe um certo tipo de personalidade de características mórbidas que expressa sintomas de doença em ambientes ansiogênicos e estressantes. Ao colocar em suspenso as atividades realizadas no trabalho vai destruindo, de forma estratégica, o campo de possibilidade do trabalho como elemento constituinte desse processo de adoecimento. 
Os enunciados sobre doenças reumáticas ou psiquiátricas não são, na própria lei sobre doença do trabalho, um impedimento ao nexo. Os direitos dos trabalhadores estão mencionados na lei no 8.213/91 sobre o Regulamento da Previdência Social e foram recentemente revisados pelo decreto no 3.081/99, resolução INSS/ no 010/99, que aprova os Protocolos Médicos para Benefícios por Incapacidade, contendo, entre os grupos de doenças: no anexo XII, grupo 13, as doenças osteomusculares do tecido conjuntivo que podem estar relacionadas com o trabalho e, dentre estas, a dor articular, a síndrome cervicobraquial, a sinovite e tenossinovite, transtornos dos tecidos moles, fibromatose de fáscia palmar, lesões do ombro, mialgias.

Uma multiplicidade de diagnósticos que se entrecruzam nas relações entre saúde e trabalho. No entanto, sabe-se que as estratégias para a negação do reconhecimento do nexo das doenças do trabalho são históricas, assim como, da luta dos trabalhadores para reverter esse quadro. As pesquisas do DIESAT (1989), ao descreverem as lutas de trabalhadores e sindicatos tornam-se documentários dos embates para o reconhecimento previdenciário das silicose, asbestoses, benzenismo, leucopenia, intoxicação por mercúrio e tantas outras.

As LER, também, estão inseridas nestes embates entre a saúde e os interesses estreitos do capital que procura usar o corpo e descartá-lo, negando sistematicamente as implicações das condições de trabalho na saúde do trabalhador e, conseqüentemente, em seu processo de adoecimento, quando este se apresenta. Temos observado em nossa pesquisa, que o INSS/RJ vem desenvolvendo uma política restritiva e economicista em relação a essa doença, tornando os benefícios acidentários assegurados por lei, não um direito do trabalhador, mas um impasse que deve ser removido.

Nesse sentido, procuram atender ao aumento de casos de trabalhadores com as LER sem correrem o risco de arcar com o ônus, como seguradora, dos prejuízos físicos e mentais de uma economia que explora intensamente a mão-de-obra, de um mercado de trabalho recessivo, de uma gerência ávida por corpos docilizados e lucros rápidos.

Tal relação mostra a radical separação entre trabalho e corpo-que-adoece. Esta separação acaba encontrando uma ancoragem na idéia de predisposição, posto que, nesse distanciamento do INSS quanto ao desenvolvimento das relações de trabalho, sejam elas prejudiciais ou não, o processo de adoecimento passa a ser encarado como efeito de alterações "psicogênicas".

Algumas falas do INSS/RJ são expressivas nesse sentido:

Nós colocamos uma interrogação dizendo que a pessoa não tem uma doença profissional ela tem sim, uma doença orgânica relacionada com características pessoais e particulares (médico perito do INSS/RJ).

Eu sou da corrente que uma doença... de uma lesão por esforços repetitivos ela não deveria ser utilizada (médico perito do INSS/RJ).

Microtrauma que eles chamam osteoarticular. Só que isso como eu estava falando, na Austrália estão provando que não tem muito a ver, isso faz parte da conseqüência da vida diária da pessoa (médico perito do INSS/RJ).

Os conflitos, reduzidos ao campo psíquico, são tratados como a expressão interna das neuroses dos indivíduos e os trabalhadores são, por este mecanismo, produzidos como neuróticos. O foco de análise não é mais uma enfermidade produzida no corpo, mas a própria intervenção na trama das emoções. Esta lógica vai criticando a abordagem ergonômica e a epidemiológica, nos casos das LER, constituindo negações e silêncios e se transformando num sistema de crenças que privilegia a evidência do referencial psicológico na leitura das dores de expressão osteomuscular.

O saber psicológico, utilizado pelos dispositivos de disciplinarização e controle das emoções individuais ou coletivas nas relações interpessoais de trabalho, vai sendo apropriado por uma moral de limites definida pela adaptação/ desadaptação social, que na prática esquadrinha os parâmetros de uma "personalidade" socialmente aceita. Esse tom avaliativo pode ser observado em nossa pesquisa, quando os trabalhadores com LER faziam referência aos colegas de trabalho e às chefias que os tratavam como "LERdo" e nos discursos dos próprios peritos quando diagnosticavam simulação ou somatização de dores.

Os relatos em saúde do trabalhador ao longo da sua história vão afirmar várias emoções: medos, ansiedades e inseguranças que matizam os processos de adoecimento. Pode-se observar, no discurso do INSS/RJ, essa mistura do somático e das emoções, quando se fala dos portadores de LER: trabalhadores que têm medo de adoecer e de sentir dor; trabalhadores que são pressionados pela angústia da possibilidade da perda do emprego; trabalhadores que inventam mecanismos de defesa para não sentir dor; 
trabalhadores de personalidade borderline que no limite do conflito são descompensados emocionalmente.

Não é uma simples forma de interdição que está nessa constituição do sujeito reconhecido como capaz e saudável para o trabalho, mas a questão da produção de si mesmo como sujeito moral e dos vínculos que pode e deve estabelecer com os outros e as estratégias de processar dependência e/ou autonomia.

A questão é saber onde procurar os fundamentos do imperativo moral e se é possível desligar as relações de trabalho e saúde deste tipo de moralidade do sujeito mórbido por tanto tempo associado ao mal, ao incapaz e ao inútil.

Reverter esse quadro implica propor uma nova análise do corpo no trabalho que, do nosso ponto de vista, expressa o adoecimento como uma forma de resistência. Não se submetendo a uma categorização que o esquadrinha ao bel-prazer do lucro (visão econômica), das relações sociais (capaz/incapaz para o trabalho) e do sujeito predisposto (imposição da culpa). Nesse sentido, afirmar o nexo do trabalho e da doença é enfatizar uma relação de força que deve ser buscada na prática dos movimentos da saúde no trabalho como uma questão de direito à vida, em todas as suas diversidades, garantindo na luta o reconhecimento das doenças do trabalho, sempre que essa possibilidade de relação existir como um fato no cotidiano do trabalhador.

A luta pela saúde no trabalho, hoje, não pode ainda prescindir da luta pelo reconhecimento da doença no cotidiano de trabalho, pois ela marca no corpo o seu próprio limite de resistência frente à exploração e a exclusão nesse mundo que se configura por corpos descartáveis e intercambiáveis em sua disponibilidade a serviço do ideário de uma saúde capitalizada que institui no corpo uma pré-morbidade.

\section{Referências bibliográficas}

Awerbuch M 1985. RSI or “Kangaroo Paw”. The Medical Journal of Australia, Fev. 4; vol. 142: 237-238.

Bell DS 1989. Repetition strain injury: an iatrogenic epidemic of simulated injury. The Medical Journal of Australia. Sep. 4; vol. 151: 280-284.

Birman J 1978. A psiquiatria como discurso da moralidade. Graal, Rio de Janeiro.

Birman J 1980. Enfermidade e loucura. Campus, Rio de Janeiro.

Braga JC \& Paula SG 1981. Saúde e previdência. Estudos de política social. Cebes-Hucitec, São Paulo.

Cleland LG 1987. RSI: a model of social iatrogenesis. The Medical Journal of Australia, Sep 7; vol. 147: 236-239.

Cullum 1989. Carta ao editor. The Medical Journal of Australia. Nov. 20; vol. 151

Cunha MC1986. O espelho do mundo. Paz e Terra, Rio de Janeiro.

Dickinson I 1989. Carta ao editor. The Medical Journal of Australia. Nov. 20; vol. 151.

Diesat 1989. Insalubridade. Morte lenta no trabalho. Oboré, São Paulo.

Diesat 1981. Boletim DIESAT. Ano 1, número 2, julhoagosto.

Diesat 1984. De que adoecem e morrem os trabalhadores. Ribeiro HP e Lacaz FA (org.) IMESP, São Paulo.
Ferguson D 1987. "RSI": putting the epidemic to rest. The Medical Journal of Australia. Sep. 7; Vol. 147: 213-214.

Foucault M 1988. História da sexualidade 1. A vontade de saber. Graal, Rio de Janeiro.

Hadler N 1986. Industrial rheumatology. The Medical Journal of Australia. Fev. 17; Vol. 144.

Hall W 1988. Repetition strain injury in Australian epidemic of upper limb pain. Social Science Medicine, 27(6): 645-649.

Hay K 1986. Carta ao editor. The Medical Journal of Australia. July, 21; vol. 145.

Hopkins A 1986. Carta ao editor. The Medical Journal of Australia. Nov. 20; vol. 151.

Lucire Y 1986. Neurosis in the workplace. The Medical Journal of Australia. vol. 145: 323-327.

Quintner J 1989. The pain of RSI. The central issue. Australian Family Physician 18 (12): 1542-47.

Resolução INSS/no 010/99. Decreto no 3.081/99.

Ribeiro HP \& Lacaz FAC (orgs.) 1985. De que adoecem e morrem os trabalhadores? IMESC/Diesat, São Paulo, $236 \mathrm{pp}$.

Roberts JR 1989. Carta ao editor. The Medical Journal of Australia. Nov. 20; Vol. 151

Sobre o Regulamento da Previdência Social 1981. Lei no $8.213 / 91$. 